\title{
Lasso-O Measuring Tape
}

National Cancer Institute

\section{Source}

National Cancer Institute. Lasso-O Measuring Tape. NCI Thesaurus. Code C81310.

A measuring tape frequently used to measure head circumference in newborns. 